\title{
Adsorption of Silver Ions from Aqueous Solution onto Thiol Modified Polyvinyl Alcohol Nanofibers
}

\author{
Duy Nam Phan ${ }^{1}$, Yohei Hasegawa ${ }^{1}$, Kyung Hun Song ${ }^{2}$, Hoik Lee ${ }^{1 *}$ and Ick Soo Kim ${ }^{1 *}$ \\ ${ }^{1}$ Nano Fusion Technology Research Group, Shinshu University, Japan \\ ${ }^{2}$ Department of Clothing \& Textiles, Pai Chai University, Korea \\ *Corresponding author: Hoik lee, Ick Soo Kim, Nano Fusion Technology Research Group, Division of Frontier Fibers, Institute for Fiber Engineering \\ (IFES), Interdisciplinary Cluster for Cutting Edge Research (ICCER), Shinshu University, Tokida 3-15-1, Ueda, Nagano, 386-8567, Japan
}

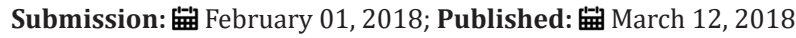

\begin{abstract}
The crosslinked polyvinyl alcohol (PVA) with glutaraldehyde nanofibers was modified by the esterification of hydroxyl group on PVA with the carboxyl group of 3-mercaptopropionic acid under hydrochloric acid in aqueous environment. The thiol-modified nanofiber mat can absorb the silver ions dissolved in water. Surface morphology of prepared nanofiber mats were observed by scanning electron microscopy. The cross linking between PVA and glutaraldehyde and the thiol groups on the nanofibers after esterification reaction were confirmed by Fourier Transform Infrared Spectroscopy. The quantitative estimation of silver particle adsorbed onto the resultant nanofiber mat was performed by UV-Vis spectroscopy and inductively coupled plasma optical emission spectrometer (ICP-OES). The maximum adsorption volume was found to be $26.2 \mathrm{mgg}^{-1}$.
\end{abstract}

Keywords: Adsorption; Silver; Thiolate; Crosslinked nanofiber; Silver adsorption

\section{Introduction}

The increase in water pollution caused by metallic elements is of great concern because of their threat to the global ecosystem due to its persistence in the environment and bio accumulating tendency in living species [1,2]. There are many metals commonly found in the environment. They might not be harmful for human health when human exposed in small amount, but they can pose a danger when a large amount of metal accumulated in human body. Prolonged accumulation of toxic metals can damage the function of the brain, lungs, kidney, liver and other organs. Long term exposure can lead to gradually progress a physical, muscular, and neurological degenerative processes, initiating diseases such as Parkinson, Alzheimer and even cancer [3,4]. Silver is one of the most studied materials due to their broad spectrum of applications in various fields, including food, healthcare, medical and industrial purposes [5]. Among the commercially available nanomaterials, silver nanoparticles are the most utilized nanomaterial owing to its attractive properties, such as catalytic effects, antibacterial activity, optical response, and electrochemical properties [6-10].

Although the unique physical and chemical properties of silver, silver implication on human health and environment is not still considered completely $[11,12]$. It was reported that silver nanoparticles can cause adverse effects on humans and environment due to its toxicity $[13,14]$. Moreover, silver also has toxicity on organisms including viruses, bacteria or human cells [15-18]. Therefore, a great interest regarded the removal of metal ions from wastewater including silver ions has been grown. Conventional methods for heavy metal removal from wastewater include reduction, precipitation, ion exchange, filtration, electrochemical treatment, membrane technology and evaporation technology, but they are generally ineffective or expensive $[19,20]$. Nanofiber is a promising material for removing target material due to its high specific surface area, a large number of surface functional groups, and stability, making them promising adsorbent materials $[21,22]$. It is expected to be a good adsorbent for pollutants due to it physical or chemical adsorption abilities. The most widely utilized method for manufacturing nanofiber is electro spinning due to the effective and facile fabrication process $[23,24]$.

In this study, we introduce the fabrication of crosslinked nanofiber mat using the electro spinning for the removal of silver ions from the aqueous solution. We choose the PVA for adsorption matrix due to is a simple structure with hydroxyl group which can be further chemically modified with thiol groups via esterification. First, PVA nanofiber was chemically crosslinked with glutaraldehyde to give an in solubility in aqueous solution. And then, the crosslinked PVA nanofiber was further modified with 3-mercaptopropionic acid to incorporated thiol which can act as strong ligating groups for metal ions. We successfully introduced the thiol functionality on crosslinked PVA nanofiber, and investigated the adsorption activity of the resultant nanofiber toward silver ions. This work can 
provide an effective way for adsorbing silver ions, which can make a promising candidate for metal adsorbing material.

\section{Materials and methods}

\section{Materials}

PVA with average molecular weight of $85000-124000 \mathrm{~g}$ mol-
1 was provided by the Sigma Aldrich. Silver nitrate $\left(\mathrm{AgNO}_{3}\right.$, purity is 99.8\%), 3-Mercaptopropionic acid (MPA, purity is 99\%), hydrochloric acid ( $\mathrm{HCl}, 35 \sim 37 \mathrm{wt} \%)$, glutaraldehyde solution (GA, $25 \mathrm{wt} \%$ ) were purchased from Wako Pure Chemical Industries, Ltd., Osaka, Japan. Distilled water was used for preparation of solutions. All chemicals were used as received without further purification.

\section{Nanofiber fabrication}

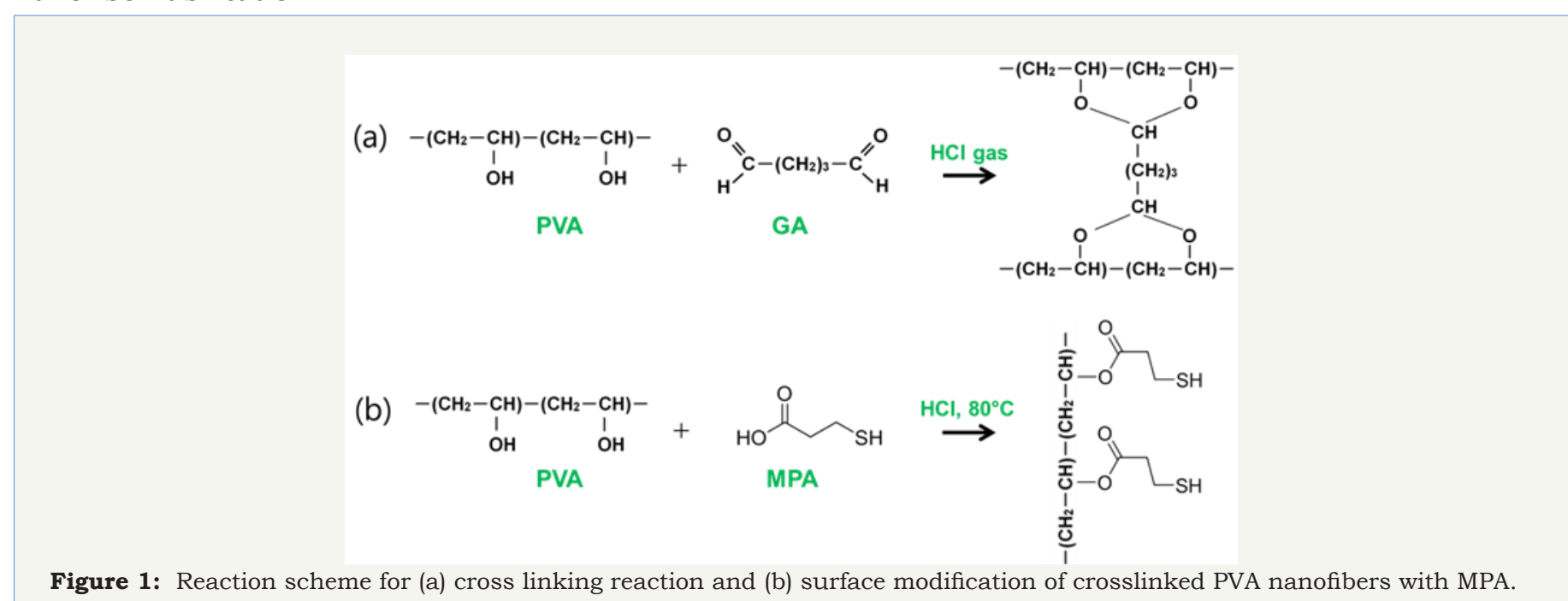

PVA was fully dissolved in distilled water with the concentration of $8 w t \%$ under vigorous stirring at $50{ }^{\circ} \mathrm{C}$ temperature for $12 \mathrm{hrs}$, and then GA solution was added into the prepared PVA solutions with weight ratio of 1:4 GA: PVA at room temperature for $12 \mathrm{hrs}$ under vigorous stirring. The prepared solution was filled in a $20 \mathrm{~mL}$ plastic syringe fitted with a needle and set up in the electro spinning apparatus. The collector was located $15 \mathrm{~cm}$ apart from the capillary tip. A syringe pump was used to feed the prepared PVA solution with a flow rate of $0.2 \mathrm{mLh}^{-1}$. It was observed that stable jets formed when an applied voltage of $13 \mathrm{kV}$ was applied and at room temperature with humidity of $40 \%$. The resultant PVA nanofiber mat was placed in a transparent glass container where $\mathrm{HCl}$ solution ( $2 \mathrm{~mL}, 8 \mathrm{M})$ located for cross linking reaction. The container was sealed, and a stirring hot plate placed at $60{ }^{\circ} \mathrm{C}$. The cross linking reaction between hydroxyl groups of PVA and aldehydes groups of GA to form acetal bond occurred for 1 min (Figure 1a).

The crosslinked PVA nanofiber was further modified with MPA for introducing thiol functionality to nanofiber through the esterification (Figure 1b). The crosslinked PVA nanofiber mat $(0.5 \mathrm{~g})$ was kept at $80{ }^{\circ} \mathrm{C}$ in $50 \mathrm{ml}$ distilled water, and then a mixture of MPA $(10 \mathrm{~mL})$ and $\mathrm{HCl}(0.4 \mathrm{~mL}, 1 \mathrm{M})$ was dropped in over a period of $20 \mathrm{~min}$. The temperature was sustained at $80^{\circ} \mathrm{C}$ for $8 \mathrm{~h}$, and then cooled at room temperature. The nanofiber mat was washed with distilled water several times to remove excessive amount of acid until reaching neutral $\mathrm{pH}$ and dried.

\section{Characterization}

The morphology and diameter characteristic of PVA nanofiber, crosslinked PVA nanofiber, the crosslinked thiol-PVA(TPVA) nanofiber before and after adsorption were confirmed by scanning electron microscopy (JSM-6010LA,JEOL, Japan) with an accelerating voltage of $10 \mathrm{kV}$. All samples were coated with platinum for electric currents to run over the surfaces of nanofibers before the observation. Fourier Transform Infrared spectrophotometer (IR Prestige-21, Shimadzu, Japan) was employed to determine the types of functional groups presenting in the nanofiber mat. The absorption spectra were recorded at room temperature over a wavelength range of 700 to $4000 \mathrm{~cm}^{-1}$.The quantitative measurement of nanoparticles was carried out by UV-Vis absorption spectra recorded on a UV-visible spectrophotometer (UV-2700, Shimadzu, Japan) and inductively coupled plasma optical emission spectrometry on SPS 3100 ICP-OES (Hitachi High-Tech Science Corporation, Tokyo, Japan).

To evaluate the adsorption ability using batch adsorption method at room temperature, the TPVA $(150 \mathrm{mg})$ nanofiber mat was immersed to $10 \mathrm{~mL}$ of $\mathrm{AgNO}_{3}$ solution $(0.01 \mathrm{M})$ in a $20 \mathrm{~mL}$ glass vial with a screw cap. The whole mixture was kept for constant shaking of $24 \mathrm{~h}$. And then, the nanofiber mat was removed from vial, and the percentage of the extracted Ag ions was calculated from the remained solution. The quantification of Ag ions was analyzed by UV-Vis spectroscopy and ICP-OES with $\mathrm{AgNO}_{3}$ solutions before and after adsorption.

\section{Results and Discussion}

The morphology of the PVA nanofibers, the crosslinked PVA nanofiber, and TPVA nanofiber before and after adsorption of silver ion were examined by SEM, as shown in Figure 2. The PVA nanofibers are randomly oriented without any bead formation, and the surfaces are smooth and uniform with average diameters $380 \pm 12 \mathrm{~nm}$. PVA nanofiber mat is a hydrophilic, therefore, cross 
linking reaction is necessary to perform the adsorption of silver in an aqueous medium. The presence of hydrogen chloride gas facilitates the formation of crosslinked network inside PVA nanofibers. The entangled fibers were observed in the crosslinked PVA nanofiber mat as a result of the cross linking reaction as presented in Figure $2 b$.

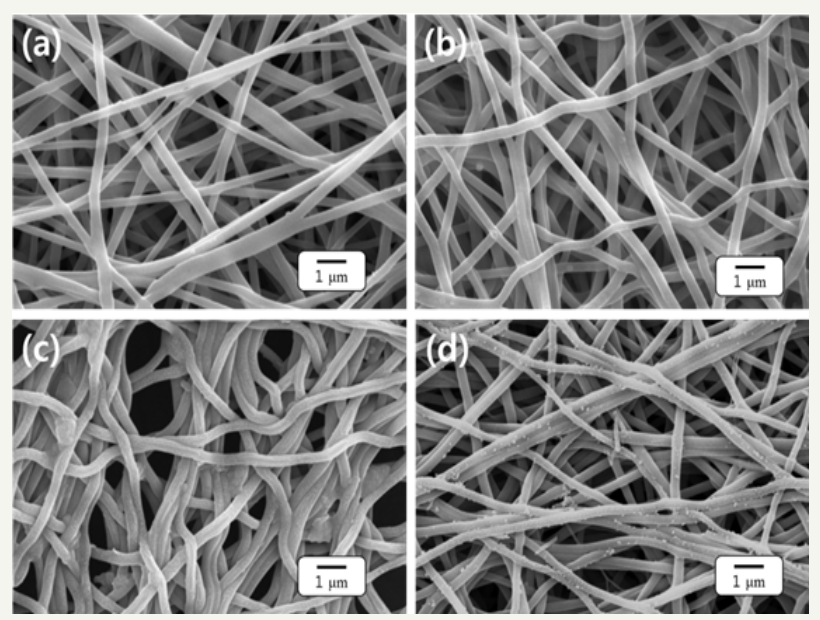

Figure 2: Morphology studies of (a) PVA nanofibers, (b) crosslinked PVA nanofibers, (c) TPVA nanofibers and (d) TPVA nanofibers after silver adsorption.

It is plausible that the adsorption capacity of metal ions greatly depends on functional groups presented on the surface of the nanofibers [25]. In order to increase the adsorption efficacy, the hydroxyl groups on PVA nanofiber were modified with MPA. The carboxyl group of the MPA reacts with hydroxyl group on the PVA backbone to form ester link ages as illustrated in Figure 1b. It is worth noting that the TPVA nanofiber are slightly shrunk in comparison with the crosslinked PVA nanofiber as a result of the formation of disulfide cross links between the sulfur groups of TPVA nanofiber (Figure 2c).

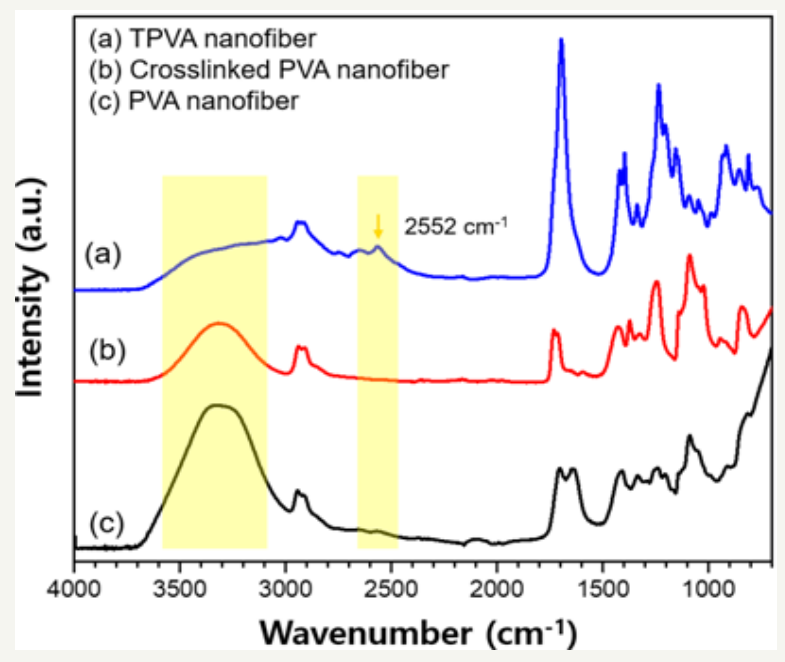

Figure 3: Representative FT-IR spectra for TPVA NFs, crosslinked PVA NFs and PVA NFs.

The surface modification with MPA was characterized by FT-IR spectroscopy (Figure 3a). FT-IR spectrum of the TPVA nanofiber exhibited a characteristic absorption associated with the stretching mode of the SH group at $2552 \mathrm{~cm}^{-1}$ [26]. The broad adsorption at $3000-3600 \mathrm{~cm}^{-1}$ corresponds to the $-\mathrm{OH}$ stretching vibrations [27]. We observed a relative decrease in the amount of hydroxyl groups after the cross linking reaction and further reduction after the esterification with MPA, which indicated that the $-\mathrm{OH}$ was consumed in both chemical reactions.

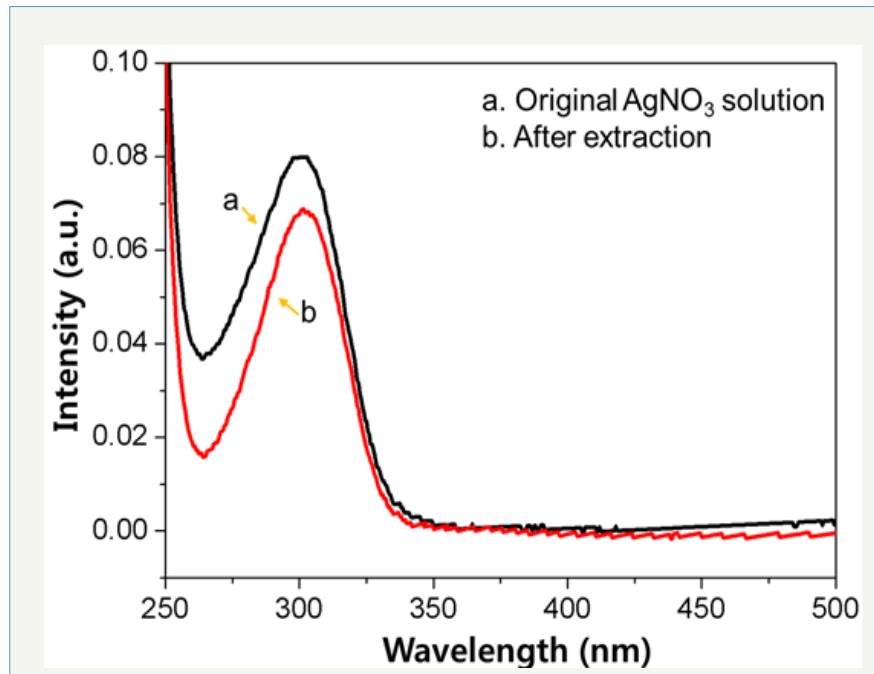

Figure 4: Representative UV-Vis spectra of the $\mathrm{AgNO}_{3}$ original solution and after extraction.

The silver ion adsorption capacity of TPVA nanofiber mat was investigated with $\mathrm{AgNO}_{3}$. For this, $150 \mathrm{mg}$ of nanofiber mat was immersed in $\mathrm{AgNO}_{3}$ solution $\left(0.01 \mathrm{molL}^{-1}\right)$ for $24 \mathrm{hrs}$. The quantification of silver ions solutions before and after adsorption was carried out using an ICP-OES and UV-VIS spectrum at room temperature. Figure 4 represents the UV-Vis spectra of silver ions before and after adsorption on TPVA nanofiber. The maximum adsorption value was found equal to $26.2 \mathrm{mg} \mathrm{g}^{-1}$ by ICP-OES. The result indicates that the silver ions are absorbed by thiol functional groups of TPVA nanofiber. The adsorption of metal ions on the surface of the adsorbents was confirmed with SEM images. Figure $2 \mathrm{~d}$ displays the SEM image of TPVA nanofiber after the extraction of silver ions on the surface of the nanofiber. It is strongly suggested that the silver ions were adsorbed on the nanofibers surface with agglomeration and aggregation and distributed throughout the nanofiber mat.

\section{Conclusion}

An approach for the chemical modification of PVA nanofibers for the water remediation was investigated. The resultant nanofibers were successfully prepared by electro spinning PVA nanofibers and subsequent following two reactions; cross linking with GA in gaseous $\mathrm{HCl}$, and esterification with MPA under the presence of $\mathrm{HCl}$ acid. The fabricated TPVA nanofiber mat was analyzed by SEM and FT-IR. FT-IR spectra demonstrated that thiol groups were modified successfully onto the surface of the nanofibers. These nanofibers were used for the silver ions adsorption from the aqueous solution and showed the affinity towards silver ions. 


\section{References}

1. Islam MS, Ahmed MK, Raknuzzaman M, Habibullah MM (2015) Heavy metal pollution in surface water and sediment: A preliminary assessment of an urban river in a developing country. Ecological Indicators 48: 282291.

2. Vasudevan S, Oturan MA (2014) Electrochemistry: as cause and cure in water pollution-an overview. Environmental Chemistry Letters 12(1): 97-108.

3. Dixit R, Wasiullah D, Malaviya K, Pandiyan U, Singh A, et al. (2015) Bioremediation of heavy metals from soil and aquatic environment: An overview of principles and criteria of fundamental processes. Sustainability 7(2): 2189-2212.

4. Jaishankar M, Tseten T, Anbalagan N, Mathew BB, Beeregowda KN (2014) Toxicity, mechanism and health effects of some heavy metals. Interdiscip Toxicol 7: 60-72.

5. Zare Y, Shabani I (2016) Polymer/metal nano composites for biomedical applications. Materials Science and Engineering: C 60: 195-203.

6. Parameshwaran R, Kalaiselvam S (2014) Energy conservative air conditioning system using silver nano-based PCM thermal storage for modern buildings. Energy and Buildings 69: 202-212.

7. Abbasi E, Milani M, Fekri AS, Kouhi M, Akbarzadeh A, et al. (2016) Silver nanoparticles: Synthesis methods, bio-applications and properties. Crit Rev Microbiol 42(2): 173-180.

8. Cheng L, Zhang K, Melo MAS, Weir MD, Zhou X, et al. (2012) Anti-biofilm dentin primer with quaternary ammonium and silver nanoparticles. J Dent Res 91(6): 598-604.

9. Zhang K, Melo MAS, Cheng L, Weir MD, Bai Y, et al. (2012) Effect of quaternary ammonium and silver nano particle-containing adhesives on dentin bond strength and dental plaque microcosm bio films. Dent Mater 28(8): 842-852.

10. Jatoi AW, Jo YK, Lee H, Oh SG, Hwang DS, et al. (2017) Antibacterial efficacy of poly (vinyl alcohol) composite nanofibers embedded with silver-anchored silica nanoparticles. J Biomedical Mater Res B Appl Biomater.

11. Gliga AR, Skoglund S, Odnevall WI, Fadeel B, Karlsson HL (2014) Sizedependent cytotoxicity of silver nanoparticles in human lung cells: the role of cellular uptake, agglomeration and Ag release. Part Fibre Toxicol 11: 11-28.

12. Munger MA, Radwanski P, Hadlock GC, Stoddard G, Shaaban A, et al. (2014) In vivo human time-exposure study of orally dosed commercial silver nanoparticles, Nanomedicine 10(1): 1-9.

13. Ahn JM, Eom HJ, Yang X, Meyer JN, Choi J (2014) Comparative toxicity of silver nanoparticles on oxidative stress and DNA damage in the nematode, caenorhabditis elegans. Chemosphere 108: 343-352.

14. Bar IO, Albrecht RM, Fako VE, Furgeson DY (2009) Toxicity assessments of multisized gold and silver nanoparticles in zebrafish embryos. Small 5(16): 1897-1910.
15. Blaser SA, Scheringer M, MacLeod M, Hungerbühler K (2008) Estimation of cumulative aquatic exposure and risk due to silver: contribution of nano-functionalized plastics and textiles. Sci Total Environ 390(2-3): 396-409.

16. Dos Santos CA, Seckler MM, Ingle AP, Gupta I, Galdiero S, Galdiero M, et al. (2014) Silver nanoparticles: therapeutical uses, toxicity, and safety issues. J Pharm Sci 103(7): 1931-1944.

17. Choi O, Hu Z (2008) Size dependent and reactive oxygen species related nanosilver toxicity to nitrifying bacteria. Environ Sci Technol 42(12): 4583-4588.

18. Carlson C, Hussain SM, Schrand AM, Braydich SLK, Hess KL, et al. (2008) Unique cellular interaction of silver nanoparticles: size-dependent generation of reactive oxygen species. J Phys Chem B 112(43): 1360813619.

19. Sun S, Yang J, Li Y, Wang K, Li X (2014) Optimizing adsorption of Pb(II) by modified litchi pericarp using the response surface methodology. Ecotoxicology and Environmental Safety 108: 29-35.

20. Soleymanzadeh M, Arshadi M, Salvacion JWL, Salimi VF (2015) A new and effective nano bio composite for sequestration of Cd(II) ions: Nanoscale zero valent iron supported on sineguelas seed waste. Chemical Engineering Research and Design 93: 696-709.

21. Lee H, Kim M, Sohn D, Kim SH, Oh SG, et al. (2017) Electrospun tungsten trioxide nanofibers decorated with palladium oxide nanoparticles exhibiting enhanced photo catalytic activity. RSC Advance 7(10): 61086113.

22. Lee H, Koo JM, Sohn D, Kim IS, Im SS (2016) High thermal stability and high tensile strength terpolyester nanofibers containing bio based monomer: fabrication and characterization. RSC Advance 6(46): 4038340388.

23. Lee H, Watanabe ZK, Kim M, Gopiraman M, Song KH, et al. (2016) Hand spinning enabled highly concentrated carbon nano tubes with controlled orientation in nanofibers. Scientific Reports 6: 37590.

24. Lee H, Xu G, Kharaghani D, Nishino M, Song KH, et al. (2017) Electrospun tri-layered zein/PVP-GO/zein nanofiber mats for providing biphasic drug release profiles. Int J Pharm 531(1): 101-107.

25. Chao HP, Chang CC, Nieva A (2014) Biosorption of heavy metals on Citrus maxima peel, passion fruit shell, and sugarcane bagasse in a fixedbed column. Journal of Industrial and Engineering Chemistry 20(5): 3408-3414.

26. Liu C, Li T, Zhang J, Chen S, Xu Z, et al. (2016) Preparation and properties of phosphorous nitrogen containing UV-curable polymeric coatings based on thiol-ene click reaction. Progress in Organic Coatings 90: 2127.

27. Ajitha B, Kumar Reddy YA, Reddy PS, Jeon HJ, Ahn CW (2016) Role of capping agents in controlling silver nanoparticles size, antibacterial activity and potential application as optical hydrogen peroxide sensor RSC Advances 6(42): 36171-36179.
Creative Commons Attribution 4.0 International License

For possible submissions Click Here Submit Article

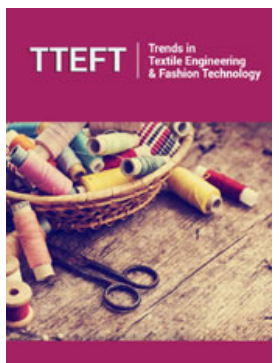

Trends in Textile Engineering \& Fashion Technology

\section{Benefits of Publishing with us}

- High-level peer review and editorial services

- Freely accessible online immediately upon publication

- Authors retain the copyright to their work

- Licensing it under a Creative Commons license

- Visibility through different online platforms 